\title{
MINIREVIEW
}

\section{Serotonin transporter polymorphisms and panic disorder}

\author{
Johannes Schumacher ${ }^{1}$ and Jürgen Deckert ${ }^{2 *}$
}

\begin{abstract}
Panic disorder (PD) is the most common anxiety disorder. Although PD seems to occur unprovoked and the underlying etiology is not well understood, studies have consistently shown that genetic factors explain approximately $48 \%$ of the variance. Moreover, family and twin studies support the view that the majority of PD cases have a complex genetic basis. Promising findings have most recently implicated the polymorphisms at the $3^{\prime}$ end of the serotonin transporter gene SLC6A4 as PD risk variants. If independent studies can replicate the observed association with the SLC6A4 variants and their functional effects on gene expression, this would have a great impact on our understanding of the disease pathophysiology and would provide opportunities to investigate genotype-phenotype correlations.
\end{abstract}

\section{The genetics of panic disorder}

Panic disorder (PD) has a population prevalence of 3.4 to $4.7 \%$ and is the most common anxiety disorder [1,2]. According to the American Psychiatric Association, PD is defined as an episode of abrupt, intense fear accompanied by additional physiological or cognitive symptoms. Other anxiety disorders and also mood and substance-use disorders are frequently observed as comorbidities [3,4]. Family and twin studies have consistently shown that genetic factors explain approximately $48 \%$ of the variance in the disease [5], and segregation analyses support the view that the majority of PD cases have a complex genetic basis. This is also highlighted by several animal breeding experiments, which reveal that anxiety or emotional activity analogous to panic and anxiety is controlled by multiple genes, possibly in

*Correspondence: Deckert_J@klinik.uni-wuerzburg.de

2Department of Psychiatry, Psychosomatics and Psychotherapy, University of

Würzburg, Füchsleinstrasse 15, 97080 Würzburg, Germany

Full list of author information is available at the end of the article varying combinations [6]. However, the genetic architecture underlying PD is heterogeneous and differs between cases. For example, the degree of genetic complexity and the pattern of genes involved might be different in familial versus non-familial, early-versus late-onset cases or when different co-morbid conditions, gender and potential intermediate or sub-phenotypes are considered.

On the molecular genetic level, linkage and candidate gene studies have been used for the genetic analysis of $\mathrm{PD}$, and several potential linkage loci and tentative associations with candidate genes have been found [7]. For several reasons, serotonergic neurotransmission, and especially the serotonin transporter gene SLC6A4, has attracted attention in the PD research field. Selective serotonin reuptake inhibitors (SSRIs) that target SLC6A4 are commonly used and effective treatments for PD [8]. In addition, mouse experiments have shown that SLC6A4 underexpression leads to anxiety-like behavior [9], which would be in accordance with human studies that have found decreased SLC6A4 expression in brains of PD patients [10].

On the genomic level, SLC6A4 is located on chromosome 17q11 and consists of 15 exons. A large amount of genetic variation has been observed in SLC6A4. An insertion-deletion polymorphism in the promoter region of SLC6A4, called 5-HTTLPR, has attracted particular attention because it has been shown that this polymorphism alters gene and protein expression and the low-expressing short variant has been associated with anxiety [11]. Moreover, an association has been found, in healthy individuals as well as in patients with major depression, between 5-HTTLPR and increased amygdala activation in response to fearful stimuli [12-14]. However, most PD genetic association studies have failed to find an association between 5-HTTLPR variants or amygdala activation and panic disorder [15-17].

\section{The role of a 3' SLC6A4 polymorphism in PD}

A recently published study by Gyawali et al. [18] reports evidence that SLC6A4 might contribute to the development of PD by a mutation other than 5-HTTLPR. Their study [18] followed findings [19] of an association between $\mathrm{PD}$ and polymorphisms located in the 3' untranslated 
region (UTR) of SLC6A4. None of these 3' UTRassociated variants showed linkage disequilibrium to 5-HTTLPR, suggesting an independent SLC6A4 locus at the 3' end of the gene. It is known that the SLC6A4 3' UTR is expressed in two alternative forms that differ by the presence or absence of a 123-bp element [20] and the more 3' (distal) form contains an additional polyadenylation signal. Gyawali et al. [18] hypothesized that one particular SNP - rs3813034 - located within this signal would alter the usage of this form relative to the more 5 , (proximal) form. To test this hypothesis, the authors [18] analyzed 65 post mortem human brain samples and found that in brains expressing one of the rs3813034 alleles - coding for G - the relative expression of the distal to the proximal SLC6A4 form was significantly lower than that of brain samples carrying the alternative $(\mathrm{T})$ allele. The same effect was seen in 71 human lymphoblast cultures. The authors [18] also found evidence that gender-specific effects contributed to the observed allelespecific expression differences. The distal form of $S L C 6 A 4$ was less expressed in brain samples from females than in those from males. To ensure that the genderspecific association is a true positive finding, the authors [18] analyzed both expressed SLC6A4 isoforms in brains of male and female mice. In this dataset they also observed gender differences similar to those seen in humans, with a lower expression of the distal SLC6A4 isoform in female mouse brains.

Gyawali et al. [18] also examined whether rs3813034 is itself the variant causing the observed SLC6A4expression differences. Using a functional approach, they cloned both forms of the 3' SLC6A4 UTR into plasmids; one construct encoded allele $\mathrm{G}$ and the other one allele $\mathrm{T}$ of rs3813034, and the remaining sequence was identical. The relative expression of the two polyadenylation forms was then quantified and the authors [18] observed that the G allele of rs3813034 caused significantly lower usage of the distal polyadenylation form than allele $\mathrm{T}$.

Finally, rs3813034 was tested for PD association in a large case-control study $(n=307$ PD patients and 544 controls) [18]. The G allele - associated with lower expression of the distal SLC6A4 isoform - was significantly more frequent in patients (51\%) than in controls (44\%; $P=0.002$ ) and thereby found to be the PD risk allele. This effect became stronger when the participants were stratified by gender. The risk allele was significantly more frequent in female PD patients (51\%) than female controls $(42 \%)(P=0.003)$, whereas no G-allele association was observed in males $(P=0.233)$ [18]. The finding was in accordance with the expression experiments, in which lower expression levels of the distal SLC6A4 form were observed in female brain samples from both humans and mice.

\section{Conclusions and perspectives}

These results are encouraging and are shedding new light on the role of SLC6A4 variation in panic disorder. Nevertheless, some questions remain. In particular, it has yet to be shown how a lower expression level of the distal $S L C 6 A 4$ isoform affects protein function quantitatively and qualitatively, for example in a gender- and/or celltype-specific manner. This is especially important because the short 5-HTTLPR, with an obvious lower protein expression, has consistently been shown not to be associated with panic disorder. Given that SLC6A4 has never been tested systematically for association and the gene might harbor several potential risk variants, possible explanations for the discrepant findings may be that the interaction between different polymorphisms has not been controlled for in previous studies or that it has gender- or cell- type-specific consequences. Studies on large PD datasets with sufficient marker coverage for extensive haplotype analyses and additional functional studies are now required.

Although these two recent reports [18,19] are evidence that candidate-gene studies can still provide some surprises, this approach has obvious limitations. In contrast, as with other disorders, modern genome-wide association studies of sufficiently large sample size will most probably lead to the identification of novel PD risk genes in the coming years and will contribute to our understanding of the underlying neurobiology of anxietyrelated disorders and behaviors [21,22]. This will increase our understanding of anxiety disorders and aid the development of better prevention strategies.

\section{Abbreviations \\ PD, panic disorder; SSRI, selective serotonin reuptake inhibitor; UTR, untranslated region.}

\section{Competing interests}

The authors declare that they have no competing interests.

\section{Authors' contributions}

The authors contributed equally to this work.

\section{Author details}

'Institute of Human Genetics, University of Bonn, Sigmund-Freud-Str. 25, 53127 Bonn, Germany. ${ }^{2}$ Department of Psychiatry, Psychosomatics and Psychotherapy, University of Würzburg, Füchsleinstrasse 15, 97080 Würzburg, Germany,

Published: 29 June 2010

\section{References}

1. Kessler RC, Stang PE, Wittchen HU, Ustun TB, Roy-Burne PP, Walters EE: Lifetime panic-depression comorbidity in the National Comorbidity Survey. Arch Gen Psychiatry 1998, 55:801-808.

2. Kessler RC, Chiu WT, Jin R, Ruscio AM, Shear K, Walters EE: The epidemiology of panic attacks, panic disorder, and agoraphobia in the National Comorbidity Survey Replication. Arch Gen Psychiatry 2006, 63:415-424.

3. Horwath E, Lish JD, Johnson J, Hornig CD, Weissman MM: Agoraphobia without panic: clinical reappraisal of an epidemiologic finding. Am J Psychiatry 1993, 150:1496-1501.

4. Kessler RC, Chiu WT, Demler O, Merikangas KR, Walters EE: Prevalence, severity, and comorbidity of 12-month DSM-IV disorders in the National 
Comorbidity Survey Replication. Arch Gen Psychiatry 2005, 62:617-627

5. Hettema JM, Neale MC, Kendler KS: A review and meta-analysis of the genetic epidemiology of anxiety disorders. Am J Psychiatry 2001, 158:1568-1578

6. Finn DA, Rutledge-Gorman MT, Crabbe JC: Genetic animal models of anxiety. Neurogenetics 2003, 4:109-135.

7. Jacob C, Domschke K, Gajewska A, et al.: Genetics of panic disorder - focus on association studies and therapeutic perspectives. Exp Rev Neurotherapeutics, in press.

8. Bakker A, van Balkom AJ, van Dyck R: Selective serotonin reuptake inhibitors in the treatment of panic disorder and agoraphobia. Int Clin Psychopharmacol 2000, 15 Suppl 2:S25-S30.

9. Holmes A, Murphy DL, Crawley JN: Abnormal behavioral phenotypes of serotonin transporter knockout mice: parallels with human anxiety and depression. Biol Psychiatry 2003, 54:953-959.

10. Esler M, Lambert E, Alvarenga M, Socratous F, Richards J, Barton D, Pier C, Brenchley C, Dawood T, Hastings J, Guo L, Haikerwal D, Kaye D, Jennings G, Kalff V, Kelly M, Wiesner G, Lambert G: Increased brain serotonin turnover in panic disorder patients in the absence of a panic attack: reduction by a selective serotonin reuptake inhibitor. Stress 2007, 10:295-304.

11. Lesch KP, Bengel D, Heils A, Sabol SZ, Greenberg BD, Petri S, Benjamin J, Müller CR, Hamer DH, Murphy DL: Association of anxiety-related traits with a polymorphism in the serotonin transporter gene regulatory region. Science 1996, 274:1527-1531

12. Hariri AR, Mattay VS, Tessitore A, Kolachana B, Fera F, Goldman D, Egan MF, Weinberger DR: Serotonin transporter genetic variation and the response of the human amygdala. Science 2002, 297:400-403.

13. Caspi A, Sugden K, Moffitt TE, Taylor A, Craig IW, Harrington H, McClay J, Mill J, Martin J, Braithwaite A, Poulton R: Influence of life stress on depression: moderation by a polymorphism in the 5-HTT gene. Science 2003 301:386-389.

14. Dannlowski U, Ohrmann P, Bauer J, Deckert J, Hohoff C, Kugel H, Arolt V, Heindel W, Kersting A, Baune BT, Suslow T: 5-HTTLPR biases amygdala activity in response to masked facial expressions in major depression. Neuropsychopharmacology 2008, 33:418-424.

15. Deckert J, Catalano M, Heils A, Di Bella D, Friess F, Politi E, Franke P, Nöthen MM, Maier W, Bellodi L, Lesch KP: Functional promoter polymorphism of the human serotonin transporter: lack of association with panic disorder. Psychiatr Genet 1997, 7:45-47.
16. Domschke K, Braun M, Ohrmann P, Suslow T, Kugel H, Bauer J, Hohoff C, Kersting A, Engelien A, Arolt V, Heindel W, Deckert J: Association of the functional -1019C/G 5-HT1A polymorphism with prefrontal cortex and amygdala activation measured with $3 \mathrm{~T} \mathrm{fMRI}$ in panic disorder. Int $J$ Neuropsychopharmacol 2006, 9:349-355.

17. Blaya C, Salum GA, Lima MS, Leistner-Segal S, Manfro GG: Lack of association between the serotonin transporter promoter polymorphism (5-HTTLPR) and panic disorder: a systematic review and meta-analysis. Behav Brain Funct 2007, 3:41.

18. Gyawali S, Subaran R, Weissman MM, Hershkowitz D, McKenna MC, Talati A, Fyer AJ, Wickramaratne P, Adams PB, Hodge SE, Schmidt CJ, Bannon MJ, Glatt CE: Association of a polyadenylation polymorphism in the serotonin transporter and panic disorder. Biol Psychiatry 2010, 67:331-338.

19. Strug L, Suresh R, Fyer AJ, Talati A, Adams PB, Li W, Hodge SE, Gilliam TC, Weissman MM: Panic disorder is associated with the serotonin transporter gene (SLC6A4) but not the promoter region (5-HTTLPR). Mol Psychiatry 2010, 15:166-176.

20. Battersby S, Ogilvie AD, Blackwood DH, Shen S, Mugit MM, Muir WJ, Teague P, Goodwin GM, Harmar AJ: Presence of multiple functional polyadenylation signals and a single nucleotide polymorphism in the $3^{\prime}$ untranslated region of the human serotonin transporter gene. J Neurochem 1999, 72:1384-1388

21. Otowa T, Yoshida E, Sugaya N, Yasuda S, Nishimura Y, Inoue K, Tochigi M, Umekage T, Miyagawa T, Nishida N, Tokunaga K, Tanii H, Sasaki T, Kaiya H Okazaki Y: Genome-wide association study of panic disorder in the Japanese population. J Hum Genet 2009, 54:122-126.

22. Erhardt A, Czibere L, Roeske D, Lucae S, Unschuld PG, Ripke S, Specht M, Kohli MA, Kloiber S, Ising M, Heck A, Pfister H, Zimmermann P, Lieb R, Pütz B, Uhr M, Weber P, Deussing JM, Gonik M, Bunck M, Keßler MS, Frank E, Hohoff C, Domschke K, Krakowitzky P, Maier W, Bandelow B, Jacob C, Deckert J, Schreiber S, et al: TMEM132D: a new candidate for anxiety phenotypes evidence from human and mouse studies. Mol Psychiatry 2010, In press (doi: 10.1038/mp.2010.41.)

doi:10.1186/gm161

Cite this article as: Schumacher J, Deckert J: Serotonin transporter polymorphisms and panic disorder. Genome Medicine 2010, 2:40 